\title{
Avian influenza viruses: a severe threat of a pandemic in children?
}

\author{
John V. Williams \\ Division of Pediatric Infectious Diseases, Vanderbilt University Medical Center, Nashville, TN, \\ USA
}

\begin{abstract}
Influenza virus is a leading cause of human respiratory illnesses, causing significant annual morbidity and mortality. The greatest severity of illness due to seasonal influenza occurs in infants less than 6 months of age and the elderly. In recent years, avian influenza virus infections with high mortality have occurred in humans. Many of these avian influenza virus infections have occurred in children, and unlike seasonal influenza, the most severe disease and highest death rates have occurred in children and young adults. Treatment and prevention options for avian influenza viruses are limited at present, although much research effort is directed toward these areas. Avian-derived influenza viruses are potential causes of pandemic influenza that could have a dramatic impact on children worldwide.
\end{abstract}

\section{Introduction}

Influenza virus is a leading cause of acute respiratory infection (ARI) worldwide and is associated with substantial morbidity and mortality [1-3]. Influenza is an important respiratory pathogen in young children, with the greatest morbidity and rates of hospitalization in young infants $[4,5]$. Several features of the biology of the influenza virus allow novel viruses to emerge into the human population, causing pandemics such as the 1918 "Spanish flu" pandemic. In recent years, highly pathogenic avian influenza viruses (HPAI) have crossed the species barrier and caused human infections with very high mortality. Of major concern to pediatricians is the fact that severe disease has occurred even in previously healthy children, a phenomenon quite distinct from seasonal influenza. HPAI viruses have the potential to cause a pandemic of virulent influenza that would have far greater effects on children than either seasonal influenza or historical pandemics. 


\section{Influenza virus}

Influenza viruses are enveloped viruses, containing a segmented RNA genome, and are members of the family Orthomyxoviridae. Influenza viruses are divided into three types: A, B, and C. Types A and B cause most human influenza in annual winter epidemics. Influenza A viruses are further divided into subtypes based on the hemagglutinin (HA) and neuraminidase (NA) genes. The WHO nomenclature for classification of influenza strains is as follows: Type (A, B, or C)/Geographic origin/Isolate \#/Year of isolation/subtype (HA and NA); e.g. A/Sydney/5/97 (H3N2). There are 16 HA subtypes and 9 NA subtypes; HA 1,2, and 3, and NA 1 and 2 typically circulate in humans. HA is the viral protein that binds to sialic acid on host cells and is a major determinant of species tropism. The HA proteins of the types that usually circulate in humans $(\mathrm{H} 1, \mathrm{H} 2$ and $\mathrm{H} 3)$ preferentially bind to the particular sialic acid moieties present on human respiratory epithelial cells. Conversely, HA in viruses that circulate in birds bind with far greater affinity to sialic acid moieties present in avian cells. The other HA and NA subtypes primarily circulate in migratory shore birds, with a few subtypes occurring naturally in horses. This provides a reservoir of novel influenza HA and NA subtypes in nature to which humans have no pre-existing immunity. The mechanisms of influenza virus replication allow for two additional sources of viral mutation, to evade host immunity or introduce completely novel subtypes. The influenza virus genome consists of segmented, single-stranded RNA molecules. The RNA polymerase enzyme that copies the genome to produce progeny virions is error-prone and, unlike DNA polymerases, has no inherent proofreading activity to correct mistakes. This leads to point mutations and progressive variation in protein sequences called 'antigenic drift'. Furthermore, viruses with segmented genomes can exchange or reassort genome segments when two different viruses infect the same cell. Reassortment leads to a complete change of the HA or NA proteins. If the new type has not circulated in humans recently, there is no pre-existing immunity in the population. The encoding of HA and NA by separate RNA molecules facilitates the reassortment of these genes in animals simultaneously infected by two different subtypes. For example, H3N1 virus has been recovered from pigs simultaneously infected with swine flu virus (H1N1) and the Hong King virus (H3N2) [6]. This abrupt change of a major immune target is called 'antigenic shift' and is a major source of pandemic strains of influenza.

\section{Pandemic influenza}

Pandemic influenza is defined as virulent human influenza that causes a global outbreak, or pandemic, of serious illness. There are three requirements for a pandemic: (1) novel HA or NA types (thus no pre-existing 
immunity in population); (2) a highly virulent strain of influenza virus; and (3) easy human-to-human spread. A worldwide influenza pandemic occurred in 1918. At least 21 million people (possibly 50-100 million) worldwide died from the ,Spanish flu' - the most devastating plague in human history. Many of the deaths were in healthy young adults and two-thirds occurred during a 4-month period [7,8]. The propensity for high mortality in previously healthy young adults was a very unusual feature of the 1918 influenza virus. Routine seasonal influenza viruses cause the highest mortality in the very young ( $<6$ months of age) and the elderly ( $>65$ years old). The increased virulence of the 1918 virus in healthy young persons has been hypothesized to be due to a "cytokine storm", but the biological mechanisms are not known. This has disturbing parallels to the mortality pattern exhibited by the recent H5N1 avian influenza viruses (see below).

Two pandemics of influenza have swept the world since the "Spanish flu" of 1918 (H1N1): the "Asian" flu pandemic of 1957 (H2N2) and the "Hong Kong" flu pandemic of 1968 (H3N2). These pandemics were milder, with an estimated 2 million deaths in 1957 and 1 million deaths in 1968. These data suggest that flu pandemics occur when the virus acquires a new HA and/or NA. The pandemic of 1957 probably infected more people than 1918. However, the availability of antibiotics to treat the secondary infections that are the usual cause of death resulted in a much lower death rate. In addition, the 1918 influenza virus was likely more virulent than the viruses from the 1957 and 1968 pandemics.

In 1997, Taubenberger et al. [9] reported partial sequences of five influenza genes recovered from the preserved lung tissue of a U.S. soldier who died from influenza in 1918. Continued work by this group led to the sequencing of the entire genome of the 1918 virus [10-16]. Phylogenetic analysis of the genomic sequence data suggests that the 1918 virus was derived from an avian-like influenza virus a short time (perhaps a few years) before the start of the pandemic, but the origin is still not known. This virus has been recreated in a highly secure biocontainment facility at the CDC using the technique of reverse engineering [15]. Studies of this recreated 1918 virus in mice suggested that the HA and NA from the 1918 strain are major determinants of virulence [15]. The contribution of other genes to virulence has not been completely determined $[12,17-20]$. However, this work suggests that a reassortant human influenza virus containing only an HA and/or NA gene from a highly virulent strain could cause severe disease and high mortality similar to that caused by the 1918 virus. This has important implications for the possible outcome of a pandemic that could occur due to avian influenza viruses.

\section{Avian influenza virus}

Avian H5N1 influenza is an emerging pathogen in both avian and human populations. Highly pathogenic strains of $\mathrm{H} 5 \mathrm{~N} 1$ have caused numerous out- 
breaks in commercial poultry flocks in recent years, with major economic consequences [21-23]. Avian influenza viruses carry novel HA types such as $\mathrm{H} 5, \mathrm{H} 7$ and $\mathrm{H} 9$ but generally do not replicate efficiently in humans. Part of this species barrier is due to the distinct preferences for HA binding to mammalian or avian sialic acids, as mentioned above. However, reassortment with human strains could allow a recombinant virus to emerge that is both highly pathogenic and highly infectious for human hosts. This reassortment between human and avian strains is thought to occur primarily in pigs, which are susceptible to infection by both strains [6]. The close proximity of humans, swine and birds in areas with endemic HPAI is of major concern as a potential source of a pandemic strain.

It is also possible for avian influenza viruses to directly infect humans. Numerous outbreaks of such novel avian influenza viruses in humans have been reported in recent years. Almost all have been epidemiologically linked to close contact with poultry, chiefly chickens or ducks, and humanto-human transmission has rarely been documented. There have been over 200 cases of human disease due to H5N1 influenza to date, with an overall $57 \%$ mortality (Tab. 1). Most of the deaths have been in previously healthy young adults and children, suggesting that $\mathrm{H} 5 \mathrm{~N} 1$ possesses significantly greater virulence than usual seasonal influenza. Again, for H5N1, virtually all cases have occurred in those with close contacts to poultry, with only a few likely cases of person-to-person transmission [24-26]. Viral determinants of virulence of the H5N1 strain have been established in birds and mice, and include a polybasic HA cleavage site (containing multiple basic amino acids) and point mutations in HA and the RNA polymerase [27]. Influenza HA must be cleaved by host proteases to be active, and normally is cleaved only by enzymes present in the respiratory tract. HPAI viruses have a polybasic HA cleavage site that is cleaved by enzymes present in many cells, thus allowing spread beyond the respiratory tract. The polybasic cleavage site also determines virulence in ferrets and cats [28-31]. These changes have not been proven to be determinants of virulence in humans, but it is likely that they are important for highly pathogenic strains.

\section{Spread of H5N1 influenza in avian populations}

Since the current strains of H5N1 influenza emerged in poultry in Southeast Asia, continuous spread to both neighboring and distant countries has been observed. Migratory waterfowl and shorebirds are carriers of avian influenza viruses, and often intermingle with domesticated fowl in open-air farms and markets. Poultry industry and governmental efforts to control the spread of H5N1 in avian populations is critical and often consists of culling large numbers of birds. These efforts have significant economic effects and have been resisted in some locations. Transmission between geographic areas has also occurred due to importation (legal and illegal) of exotic birds 
Table 1. Cumulative number of confirmed human cases of avian influenza A/(H5N1) reported to the WHO

\begin{tabular}{lcccccccccc}
\hline Country & \multicolumn{2}{c}{2003} & \multicolumn{2}{c}{2004} & \multicolumn{2}{c}{2005} & \multicolumn{2}{c}{2006} & \multicolumn{2}{c}{ Total } \\
\cline { 2 - 10 } & Cases & Deaths & Cases & Deaths & Cases & Deaths & Cases & Deaths & Cases & Deaths \\
\hline Azerbaijan & 0 & 0 & 0 & 0 & 0 & 0 & 8 & 5 & 8 & 5 \\
Cambodia & 0 & 0 & 0 & 0 & 4 & 4 & 2 & 2 & 6 & 6 \\
China & 0 & 0 & 0 & 0 & 8 & 5 & 11 & 7 & 19 & 12 \\
Djibouti & 0 & 0 & 0 & 0 & 0 & 0 & 1 & 0 & 1 & 0 \\
Egypt & 0 & 0 & 0 & 0 & 0 & 0 & 14 & 6 & 14 & 6 \\
Indonesia & 0 & 0 & 0 & 0 & 17 & 11 & 34 & 28 & 51 & 39 \\
Iraq & 0 & 0 & 0 & 0 & 0 & 0 & 2 & 2 & 2 & 2 \\
Thailand & 0 & 0 & 17 & 12 & 5 & 2 & 0 & 0 & 22 & 14 \\
Turkey & 0 & 0 & 0 & 0 & 0 & 0 & 12 & 4 & 12 & 4 \\
Vietnam & 3 & 3 & 29 & 20 & 61 & 19 & 0 & 0 & 93 & 42 \\
Total & 3 & 3 & 46 & 32 & 95 & 41 & 84 & 54 & 228 & 130 \\
\hline
\end{tabular}

Source: http://www.who.int/csr/disease/avian_influenza/country/cases_table_2006_06_20/en/ index.html ; accessed 26 June 2006.

[32]. As of 13 June 2006, influenza A (H5N1) had been reported in migratory birds or poultry flocks in Africa (Burkina Faso, Cameroon, Côte d'Ivoire, Djibouti, Egypt, Niger, Nigeria, and Sudan), Asia (Afghanistan, Azerbaijan, Cambodia, China, Georgia, Hong Kong, Kazakhstan, India, Indonesia, Iraq, Iran, Israel, Jordan, Malaysia, Mongolia, Myanmar, Palestinian Autonomous Territories, Pakistan, Thailand, Turkey, and Vietnam), and Europe (Albania, Austria, Bosnia-Herzegovina, Bulgaria, Croatia, Czech Republic, Denmark, France, Germany, Greece, Hungary, Italy, Poland, Romania, Russia, SerbiaMontenegro, Slovakia, Slovenia, Sweden, Switzerland, Ukraine, and the United Kingdom) [33]. The spread of the virus has been associated with the migration of wild birds from Asia [34], suggesting that apparently healthy birds can carry the virus over long distances [35]. Most experts consider it highly likely that H5N1 viruses will reach North and South America and intense surveillance activity is being conducted in wild bird populations. The spread of human cases closely parallels the spread in birds (Tab. 1).

\section{Epidemiology and clinical features of avian influenza in children}

Avian influenza viruses have caused a spectrum of disease in humans, including typical influenza-like illness, conjunctivitis and severe respiratory disease. More recent outbreaks, and the H5N1 virus in particular, have been 
more severe and more frequently associated with fatal illness. In general, avian influenza virus infections in children have been no less severe than in adults.

Mild respiratory disease was reported in 2 Dutch children due to reassortant human-avian influenza viruses in 1994 [6]. In 1997, a 3-year-old boy in Hong Kong died of acute respiratory failure and multiorgan system dysfunction due to an $\mathrm{H} 5$ influenza strain. Genomic sequencing and analysis of the virus showed that it was an H5N1 avian strain [36]. During that outbreak, 5 other children under the age of 18 were infected. A 13-year-old girl died of acute respiratory failure and multiorgan system dysfunction, a 2-year-old boy was hospitalized for 3 days with pneumonia and 3 other children experienced uneventful upper respiratory infection. The children who died were previously healthy. A total of 12 cases were reported, with more severe disease and higher fatality rate in the adults [37].

Outbreaks of avian influenza have continued since 1997, and have spread to broader geographic areas, particularly H5N1. There were 2 confirmed and 1 probable H5N1 cases in Hong Kong in February of 2003 [38]. A 33-year-old man developed fatal progressive respiratory failure and his 8 -year-old son recovered from respiratory disease after a prolonged hospitalization. Both had profound lymphopenia, hypoxia and consolidation of chest radiographs. The family also had a 7-year-old daughter who had died of a febrile pneumonia 1 week prior to the father and brother's illnesses, but she had not been tested for influenza.

Two cases of H9N2 avian influenza infection of humans occurred in Hong Kong, one a child, with typical influenza symptoms of fever, rhinorrhea and cough [39]. Both patients fully recovered. There was also a large outbreak of H7N7 in the Netherlands in 2003 on poultry farms, with infection of both pigs and humans [40]. There were a total of 89 human cases, primarily among poultry workers. Most of the illnesses were conjunctivitis, with only a few typical influenza-like illnesses. There was one fatality, a veterinarian who visited one of the farms and developed acute respiratory distress syndrome (ARDS). Most of the cases were attributed to direct contact with infected poultry, although there were three possible instances of person-to-person transmission.

During 2003 and 2004, there were 34 cases of confirmed human H5N1 infection in Thailand and Vietnam [41-43]. Seven of the 12 laboratory-confirmed cases in Thailand were boys age $2-13$, all of whom presented with fever, cough and tachypnea. Lymphopenia and elevated transaminases were noted in most. All 7 boys had abnormalities on chest radiograph consisting of focal or multifocal consolidation, and all required mechanical ventilation. Five of these 7 children died, and overall mortality in the Thailand outbreak was 8/12 (67\%). In January 2004, 10 human H5N1 infections were reported in Vietnam. Seven patients were less than 18 years old, with a mean age of 12 and the youngest 5 years. All patients presented with fever, tachypnea, cough, and hypoxia. Five also had diarrhea, but none of the children had 
myalgia, rash or conjunctivitis. Similar to the Thailand cases, the most common laboratory abnormalities noted were lymphopenia, thrombocytopenia and elevated transaminases. All had extensive consolidations on chest radiographs, which progressed despite aggressive therapy. All developed respiratory failure requiring mechanical ventilation, and 7/8 children died, despite aggressive supportive care and treatment with oseltamivir, ribavirin and/or steroids for ARDS.

Two other children were identified with probable or confirmed H5N1 infection during the same outbreak [44]. A 9-year-old girl presented with fever, watery diarrhea, shock and lethargy. Initial laboratory tests including cerebrospinal fluid were normal. She had fulminant shock, became comatose and died within 24 hours. No influenza tests were performed. However, 8 days later, her 4-year-old brother presented with fever, headache, vomiting and profound watery diarrhea. His initial laboratory values were remarkable only for elevated transaminases. However, he developed pneumonia and lethargy, progressing to coma, and died of respiratory failure 5 days after admission. During his hospitalization, he developed lymphopenia, thrombocytopenia, and bilateral infiltrates on chest radiograph. Cerebrospinal fluid was remarkable only for elevated protein. He was diagnosed with unexplained encephalitis, but postmortem testing detected H5N1 influenza by RT-PCR in cerebrospinal fluid, serum, throat and rectal swabs, and culture of cerebrospinal fluid grew H5N1 influenza virus. Thus, it is highly likely that his sister had been infected with H5N1. Notably, neither child initially presented with respiratory symptoms and the sister never had respiratory disease. Both had had frequent exposure to ducks and chickens at home and there were no other cases in the family.

As of April 30, 2006, a total of 205 cases of human H5N1 infection had been reported to the WHO [45]. One-half of these occurred in patients less than 20 years old, with a range from 3 months to 72 years. Twenty-one cases $(10 \%)$ were in children $<5$ years, $32(16 \%)$ were in children from 5 to 9 years, and $49(24 \%)$ were in $10-19$-year olds. There was a male predominance in the younger cases, with a male:female ratio of 1.5 in the 53 cases $<10$ years old. The sex ratio was equal in all other age groups. It is not known whether this finding reflects gender-specific epidemiological risk factors or biological differences.

\section{Clinical presentation and outcome}

The reported symptoms of avian influenza in children have ranged from typical influenza-like symptoms (e.g., fever, cough, sore throat, and muscle aches) to eye infections (conjunctivitis), pneumonia, acute respiratory distress, viral pneumonia, and other severe and life-threatening complications (Tab. 2). The majority of children have presented with fever and respiratory symptoms, although in the Vietnam cases, diarrhea was prominent. Notably, 
Table 2. Clinical features of H5N1 avian influenza in children

\begin{tabular}{lccc}
\hline Reference & {$[36]$} & {$[42]$} & {$[41,43]$} \\
\hline Number of patients & 7 & 7 & 9 \\
Male (\%) & 57 & 43 & 56 \\
Previously healthy & 71 & 100 & 87 \\
$(\%)$ & & 100 & 100 \\
Fever (\%) & 100 & 100 & 90 \\
Cough (\%) & 43 & $-*$ & 35 \\
Rhinorrhea (\%) & 71 & 100 & 69 \\
Dyspnea (\%) & $-*$ & 57 & 25 \\
GI symptoms (\%) & 29 & 100 & 100 \\
Pneumonia (\%) & 29 & 86 & 100 \\
Ventilated (\%) & 29 & 86 & 90 \\
Mortality (\%) & 29 & & \\
\hline
\end{tabular}

*Not reported.

a number of pediatric cases have presented without any respiratory symptoms but with severe gastrointestinal (GI) or neurological symptoms. A key historical element of virtually all cases is a recent exposure to domestic or wild birds. A high index of suspicion is necessary to consider the diagnosis. In most cases, the onset of symptoms occurs within 1 week of the bird exposure. The median duration of symptoms prior to hospitalization was 4 days (range 0-18 days).

Prominent laboratory findings include leukopenia (especially lymphopenia), thrombocytopenia and elevated liver transaminases (Tab. 3). Most pediatric patients do not manifest hemoconcentration; this finding and the prominent respiratory symptoms help distinguish the illness from dengue virus infection in dengue-endemic areas. Renal failure, hyperglycemia and hemophagocytosis have been noted in some patients. Most have abnormal chest radiographs at presentation. Many patients develop complications such as respiratory failure requiring assisted ventilation, ARDS, shock and multiorgan system dysfunction. Severe infections have typically progressed rapidly, with a median duration of symptoms prior to death of 9 days (range 2-31 days). The proximate cause of death is usually respiratory failure.

The overall mortality in the cumulative human H5N1 cases reported to date is $59 \%$ (Tab. 1). However, the highest mortality rates occurred in patients age 10-19 (73\%, $n=49), 20-29(65 \%, n=45), 30-39(61 \%, n=33)$ and $40-49$ years $(45 \%, n=11)$. Very high mortality rates were also observed in children $<5$ years $(43 \%, n=21)$ and $5-9$ years $(41 \%, n=32)$. The lowest rates were in the patients older than $50(18 \%, n=11)$ [45]. This distribution 
Table 3. Laboratory and radiological findings of H5N1 avian influenza in children

\begin{tabular}{lccc}
\hline Reference & {$[36]$} & {$[42]$} & {$[41,43]$} \\
\hline Leukopenia (\%) & 29 & 100 & 100 \\
Thrombocytopenia (\%) & 29 & 86 & 44 \\
Elevated transaminases (\%) & 43 & $80^{*}$ & 71 \\
Radiographic infiltrates (\%) & 29 & 100 & 100 \\
\hline
\end{tabular}

*Transaminases not reported for two patients.

is reminiscent of the mortality associated with the highly virulent 1918 pandemic virus and, again, is quite unlike the mortality curve associated with seasonal influenza. Pediatric mortality in cases reported outside of Thailand and Vietnam vary widely (Tab. 4).

Autopsy examination reveals severe lung pathology, including necrotizing diffuse alveolar damage with patchy and interstitial paucicellular fibrosis $[46,47]$. H5N1 has been detected in lung tissue by RT-PCR up to day 17 of illness. H5N1 has been isolated in respiratory specimens, blood, GI tract, and cerebrospinal fluid. However, it is not clear whether viral replication and direct cytopathology occurs in tissues outside of the respiratory tract, or whether the major systemic effects are due to cytokine responses. Virus replication was not detected outside of the lungs and tonsils during experimental infection of macaques [48]. However, the same investigators recently reported that experimental $\mathrm{H} 5 \mathrm{~N} 1$ infection of cats led to virus replication in multiple extra-respiratory tissues, including brain, liver, kidney, heart and GI tract [28]. Further studies in humans are needed to further elucidate the mechanisms of $\mathrm{H} 5 \mathrm{~N} 1$ pathogenesis.

\section{Diagnosis}

Timely diagnosis of avian influenza virus infections is critical to limit spread, initiate early therapy and alert health authorities. The usual diagnostic methods for detecting seasonal influenza $\mathrm{A}$ and $\mathrm{B}$ include rapid antigen tests, viral culture, immunofluorescent antibody assays and RT-PCR [49]. In countries where avian influenza activity has been identified or suspected, the critical issues are laboratory safety and the need to distinguish avian influenza viruses from human $\mathrm{A} / \mathrm{H} 1, \mathrm{~A} / \mathrm{H} 3$ and $\mathrm{B}$ infections. The use of rapid antigen assays may rapidly identify influenza $\mathrm{A}$ or $\mathrm{B}$ virus infection, but will not differentiate between human and avian influenza A virus subtypes. Specimens from cases of potential avian influenza should be forwarded to a national or a WHO H5 Reference Laboratory for confirmatory testing. Since limited data exist describing shedding of avian influenza virus in humans, several respiratory specimens should be collected on different 
Table 4. Pediatric cases of H5N1 infection and mortality in countries other than Thailand and Vietnam

\begin{tabular}{lccc}
\hline Country & Total no. of cases & $\begin{array}{c}\text { No. of pediatric } \\
\text { cases }(\%)\end{array}$ & $\begin{array}{c}\text { Pediatric mortality } \\
(\%)\end{array}$ \\
\hline Azerbaijan & 8 & $6(75)$ & 17 \\
Cambodia & 6 & $3(50)$ & 100 \\
China & 19 & $7(37)$ & 43 \\
Djerbouti & 1 & $1(100)$ & 0 \\
Egypt & 14 & $7(50)$ & 14 \\
Indonesia & 52 & $23(44) \#$ & 70 \\
Iraq & 2 & $1(50)$ & 100 \\
Turkey & $21^{*}$ & $19(90)$ & 21 \\
\hline
\end{tabular}

*Confirmed by laboratory testing in Turkey; 9 cases not yet confirmed by WHO testing. \#Four additional untested pediatric deaths in siblings of confirmed cases.

Source: Weekly Epidemiological Record (WER) 2005-2006, World Health Organization. Accessible at: http://www.who.int/wer/en/

days for testing. Rapid tests for the diagnosis of avian influenza infection should be used only in combination with clinical findings and exposure history, due to the unknown sensitivity of these assays for avian influenza viruses. A negative rapid test result does not exclude human infection with avian influenza viruses. Specimens from highly suspect cases should not be cultivated under routine conditions in the clinical virology laboratory, but transported to a reference laboratory under appropriate biosafety conditions for confirmatory RT-PC testing.

\section{Treatment}

The adamantane drugs, amantadine and rimantadine, block a viral ion channel protein required for cell entry and traditionally have been effective for treatment and prophylaxis of seasonal type A influenza. However, more than $90 \%$ of seasonal $\mathrm{H} 3 \mathrm{~N} 2$ viruses in the US are now resistant to the adamantanes, and in January 2006, the Centers for Disease Control and Prevention (CDC) recommended against the use of the adamantane class of antivirals for the treatment and prophylaxis of influenza in the United States until susceptibility to adamantanes has been reestablished among circulating influenza A isolates [50]. Avian H5N1 influenza strains currently circulating are frequently resistant to these agents $[51,52]$. This resistance has been shown to develop during therapy for both seasonal influenza as well as avian influenza, and it has been noted de novo in clinical and field isolates of H5N1 influenza [51, 52]. These drugs reportedly have been 
widely used in poultry flocks and it is hypothesized that this has selected for resistant isolates in the field. The resistance appears to be stable in the current $\mathrm{H} 5 \mathrm{~N} 1$ strains and it is unlikely that these drugs will have a role either in prophylaxis or treatment of avian influenza.

Neuraminidase inhibitors include oseltamivir and zanamavir; these agents inhibit the release of new viruses from infected cells and limit spread of infection from cell to cell. These drugs can reduce the severity and duration of illness caused by seasonal influenza, but are most effective when administered early in the course of illness, preferably within $48 \mathrm{~h}$ after symptom onset. Most strains of the H5N1 virus tested have been susceptible to the neuraminidase inhibitors, although resistance to oseltamivir has been reported $[53,54]$. There are no good clinical data to support the efficacy of these drugs against H5N1 influenza, but they are generally safe and well tolerated. The reported case series from Thailand showed a nonsignificant trend towards better outcome with earlier oseltamivir treatment [41]. The major limitations to the use of neuraminidase inhibitors is likely to be unavailability due to limited production capacity, and prohibitive price for under-resourced countries. The manufacturing process for oseltamivir is complex and time consuming. Although the manufacturing capacity of oseltamivir has recently quadrupled, it will take a decade to produce enough oseltamivir to treat $20 \%$ of the world's population.

The majority of H5N1-related human deaths have been due to severe pneumonia, multiorgan system dysfunction and shock resulting directly from the virus, and thus cannot be prevented with antibiotics. However, influenza is often complicated by secondary bacterial pneumonia, and antibiotics could be life saving in the case of late-onset pneumonia. The mainstay of therapy is likely to be early detection and aggressive supportive care.

\section{Vaccines}

HPAI virus outbreaks in commercial poultry flocks have spurred research into several forms of influenza vaccines. Recombinant viral-vectored vaccines encoding influenza HA have been constructed from fowlpox and vaccinia viruses [55-59]. These vaccines have shown efficacy in chickens against both low- and high-pathogenicity strains. However, safety concerns makes translation of these results to human trials difficult. Traditional influenza vaccines grown in eggs and chemically inactivated ('killed' vaccine) have been the mainstay of preventive strategies in commercial poultry [60, 61]. This is essentially the same method used to produce human influenza vaccines. Recent studies have reported the use of reverse engineering to produce vaccine strains in cultured cells that bear modified genes to attenuate virulence $[62,63]$. The reverse engineering technique is very promising in that it allows vaccines to be 'tailor-made' to respond to variation in field 
strain HA or NA proteins, and the potential to modify virus genes to alter virulence or replication characteristics [62, 64-67]. However, major limitations of both traditional and reverse-engineering approaches are: (a) the requirement to develop vaccine seed strains that replicate to high titers in embryonated eggs; (b) the necessity for vaccine production in eggs, where one egg yields approximately one dose; and (c) the purification required for egg-produced vaccine and concerns regarding poultry-associated infectious agents, such as Salmonella. Recent studies of cell-culture produced influenza vaccines may alleviate some of these obstacles [62, 68-72].

Clinical trials have been conducted with an inactivated H5N1 vaccine produced using a combination of traditional and reverse-engineering methods [73]. Reverse engineering was used to modify the polybasic HA cleavage site of an H5N1 strain. This virus was then grown in eggs and chemically inactivated. Healthy adult volunteers received two doses of the vaccine at varying dosages. Protective antibody responses were produced in slightly over half of adults who received two immunizations with $90 \mu \mathrm{g} \mathrm{HA}$ (seasonal influenza dose $15 \mu \mathrm{g} \mathrm{HA}$ ). While this trial showed some protective efficacy, the requirement for such high dosing presents a major obstacle, given the production problems and limitations of traditional egg-grown vaccines. A more recently published European trial found that a similar inactivated vaccine adjuvanted with alum ( $30 \mu \mathrm{g}$ HA) induced protective antibody responses in $67 \%$ of adults [74]. Further clinical trials of inactivated $\mathrm{H} 5 \mathrm{~N} 1$ vaccines administered with different adjuvants are underway in several sites.

Recombinant protein subunit vaccination is a strategy that has been highly successful for hepatitis B vaccine, which is produced in yeast [75]. Recombinant production allows strict quality control of all vaccine components and more straightforward quantitation of lot-to-lot variation. Recombinant influenza hemagglutinin has been produced in insect cells [7678]. Insect cell-expressed HA proteins have been tested in mice and chickens and were immunogenic and protective [79-82]. In subsequent human clinical trials, insect cell-expressed HA stimulated humoral immune responses in human vaccine trials, but required high doses [83-87]. One trial tested insect cell-expressed H5 HA and detected neutralizing antibody responses to a titer of 1:80 or greater in $52 \%$ of subjects after two doses of $90 \mathrm{mg}$.

The requirement for such high doses (45-135 $\mu \mathrm{g}$ HA) compared to inactivated seasonal influenza vaccine ( $15 \mu \mathrm{g} \mathrm{HA})$ presents a barrier to producing sufficient vaccine for large populations in the event of a pandemic. Similar to the inactivated H5N1 vaccine trial described above, the reason for the decreased immunogenicity of the insect cell-expressed protein is not clear. It may be due to a lack of previous exposure to H5 subtype virus in the subjects, who therefore would have experienced a primary rather than a primed memory response. Alternative adjuvants may be more effective at inducing robust responses to novel antigens and clinical trials of the insect cell-expressed HA with alternative adjuvants are also ongoing. 


\section{Summary}

The emergence of avian influenza viruses in the human population promotes high concern for a potential pandemic. Avian influenza viruses have extreme virulence in children, with multiorgan disease and high mortality. The majority of cases have exposure to domestic poultry and human-tohuman transmission is rare. Most children present with fever, rhinorrhea and cough, and lymphopenia, thrombocytopenia and elevated transaminases are common. Some children can present with GI disease alone. The complications of illness are severe, including respiratory failure, shock and death. Aggressive supportive care is the mainstay of treatment, although neuraminidase inhibitors may have some efficacy if used early. Suspicion for the presence of avian influenza relies heavily on epidemiological risk factors such as exposure to poultry or travel to endemic regions. The continued spread of these viruses in wild and domestic bird populations requires regular checking of institutional or governmental sources to keep abreast of rapidly changing endemic or epidemic regions. Suspected cases should be kept in strict isolation and appropriate testing obtained with the aid of local or national health departments. Preventive strategies including vaccines are in development, and unlike seasonal influenza, children appear to be a highrisk group that should be targeted for early vaccine testing.

Additional information on influenza, including avian influenza, is available at: http://www.cdc.gov/flu

Updates on the worldwide avian influenza situation are available from WHO at: http://www.who.int/csr/disease/avian_influenza/en

WHO H5 Reference Laboratory: http://www.who.int/csr/disease/avian_ influenza/guidelines/referencelabs/en/

\section{References}

1 World Health Organization (2006) Acute Respiratory Infections: Influenza. World Health Organization, Geneva

2 Neuzil KM, Mellen BG, Wright PF, Mitchel EF Jr, Griffin MR (2000) The effect of influenza on hospitalizations, outpatient visits, and courses of antibiotics in children. $N$ Engl J Med 342: 225-231

3 Neuzil KM, Zhu Y, Griffin MR, Edwards KM, Thompson JM, Tollefson SJ, Wright PF (2002) Burden of interpandemic influenza in children younger than 5 years: a 25-year prospective study. J Infect Dis 185: 147-152

4 Glezen WP, Couch RB (1978) Interpandemic influenza in the Houston area, 1974-76. N Engl J Med 298: 587-592

5 Glezen WP (1980) Considerations of the risk of influenza in children and indications for prophylaxis. Rev Infect Dis 2: 408-420

6 Claas EC, Kawaoka Y, de Jong JC, Masurel N, Webster RG (1994) Infection of children with avian-human reassortant influenza virus from pigs in Europe. Virology 204: 453-457 
7 Luk J, Gross P, Thompson WW (2001) Observations on mortality during the 1918 influenza pandemic. Clin Infect Dis 33: 1375-1378

8 Johnson NP, Mueller J (2002) Updating the accounts: global mortality of the 1918-1920 "Spanish“ influenza pandemic. Bull Hist Med 76: 105-115

9 Taubenberger JK, Reid AH, Krafft AE, Bijwaard KE, Fanning TG (1997) Initial genetic characterization of the 1918 "Spanish" influenza virus. Science 275: 1793-1796

10 Reid AH, Fanning TG, Hultin JV, Taubenberger JK (1999) Origin and evolution of the 1918 "Spanish" influenza virus hemagglutinin gene. Proc Natl Acad Sci USA 96: 1651-1656

11 Reid AH,Fanning TG, Janczewski TA, Taubenberger JK (2000) Characterization of the 1918 "Spanish" influenza virus neuraminidase gene. Proc Natl Acad Sci USA 97: 6785-6790

12 Basler CF, Reid AH, Dybing JK, Janczewski TA, Fanning TG, Zheng H, Salvatore M, Perdue ML, Swayne DE, Garcia-Sastre A et al (2001) Sequence of the 1918 pandemic influenza virus nonstructural gene (NS) segment and characterization of recombinant viruses bearing the 1918 NS genes. Proc Natl Acad Sci USA 98: 2746-2751

13 Reid AH, Fanning TG, Janczewski TA, McCall S, Taubenberger JK (2002) Characterization of the 1918 "Spanish" influenza virus matrix gene segment. $J$ Virol 76: 10717-10723

14 Reid AH, Fanning TG, Janczewski TA, Lourens RM, Taubenberger JK (2004) Novel origin of the 1918 pandemic influenza virus nucleoprotein gene. J Virol 78: 12462-12470

15 Tumpey TM, Basler CF, Aguilar PV, Zeng H, Solorzano A, Swayne DE, Cox NJ, Katz JM, Taubenberger JK, Palese P, Garcia-Sastre A (2005) Characterization of the reconstructed 1918 Spanish influenza pandemic virus. Science 310: $77-80$

16 Taubenberger JK, Reid AH, Lourens RM, Wang R, Jin G, Fanning TG (2005) Characterization of the 1918 influenza virus polymerase genes. Nature 437: 889-893

17 Tumpey TM, Garcia-Sastre A, Taubenberger JK, Palese P, Swayne DE, PantinJackwood MJ, Schultz-Cherry S, Solorzano A, Van Rooijen N, Katz JM, Basler CF (2005) Pathogenicity of influenza viruses with genes from the 1918 pandemic virus: functional roles of alveolar macrophages and neutrophils in limiting virus replication and mortality in mice. J Virol 79: 14933-14944

18 Tumpey TM, Garcia-Sastre A, Taubenberger JK, Palese P, Swayne DE, Basler CF (2004) Pathogenicity and immunogenicity of influenza viruses with genes from the 1918 pandemic virus. Proc Natl Acad Sci USA 101: 3166-3171

19 Kash JC, Basler CF, Garcia-Sastre A, Carter V, Billharz R, Swayne DE, Przygodzki RM, Taubenberger JK, Katze MG, Tumpey TM (2004) Global host immune response: pathogenesis and transcriptional profiling of type A influenza viruses expressing the hemagglutinin and neuraminidase genes from the 1918 pandemic virus. $J$ Virol 78: 9499-9511

20 Glaser L, Stevens J, Zamarin D, Wilson IA, Garcia-Sastre A, Tumpey TM, Basler CF, Taubenberger JK, Palese P (2005) A single amino acid substitution 
in 1918 influenza virus hemagglutinin changes receptor binding specificity. $J$ Virol 79: 11533-11536

21 Webster RG, Kawaoka Y, Bean WJ Jr (1986) Molecular changes in A/Chicken/ Pennsylvania/83 (H5N2) influenza virus associated with acquisition of virulence. Virology 149: 165-173

22 Horimoto T, Rivera E, Pearson J, Senne D, Krauss S, Kawaoka Y, Webster RG (1995) Origin and molecular changes associated with emergence of a highly pathogenic H5N2 influenza virus in Mexico. Virology 213: 223-230

23 Cauthen AN, Swayne DE, Schultz-Cherry S, Perdue ML, Suarez DL (2000) Continued circulation in China of highly pathogenic avian influenza viruses encoding the hemagglutinin gene associated with the 1997 H5N1 outbreak in poultry and humans. $J$ Virol 74: 6592-6599

24 Ungchusak K, Auewarakul P, Dowell SF, Kitphati R, Auwanit W, Puthavathana P, Uiprasertkul M, Boonnak K, Pittayawonganon C, Cox NJ et al (2005) Probable person-to-person transmission of avian influenza A (H5N1). N Engl $J$ Med 352: 333-340

25 Olsen SJ, Ungchusak K, Sovann L, Uyeki TM, Dowell SF, Cox NJ, Aldis W, Chunsuttiwat S (2005) Family clustering of avian influenza A (H5N1). Emerg Infect Dis 11: 1799-1801

26 World Health Organization (2006) Avian influenza - situation in Indonesia - update 14. In: Disease Outbreak News, 23 May 2006

27 Hatta M, Gao P, Halfmann P, Kawaoka Y (2001) Molecular basis for high virulence of Hong Kong H5N1 influenza A viruses. Science 293: 1840-1842

28 Rimmelzwaan GF, van Riel D, Baars M, Bestebroer TM, van Amerongen G, Fouchier RA, Osterhaus AD, Kuiken T (2006) Influenza A virus (H5N1) infection in cats causes systemic disease with potential novel routes of virus spread within and between hosts. Am J Pathol 168: 176-183; quiz 364

29 Kuiken T, Rimmelzwaan G, van Riel D, van Amerongen G, Baars M, Fouchier R, Osterhaus A (2004) Avian H5N1 influenza in cats. Science 306: 241

30 Zitzow LA, Rowe T, Morken T, Shieh WJ, Zaki S, Katz JM (2002) Pathogenesis of avian influenza A (H5N1) viruses in ferrets. J Virol 76: 4420-4429

31 Govorkova EA, Rehg JE, Krauss S, Yen HL, Guan Y, Peiris M, Nguyen TD, Hanh TH, Puthavathana P, Long HT, Buranathai C, Lim W, Webster RG, Hoffmann E (2005) Lethality to ferrets of H5N1 influenza viruses isolated from humans and poultry in 2004. J Virol 79: 2191-2198

32 Van Borm S, Thomas I, Hanquet G, Lambrecht B, Boschmans M, Dupont G, Decaestecker M, Snacken R, van den Berg T (2005) Highly pathogenic H5N1 influenza virus in smuggled Thai eagles, Belgium. Emerg Infect Dis 11: 702-705

33 World Organisation for Animal Health (2006) Update on avian influenza in animals (type H5). Available from: http://www.oie.int/downld/avian\%20influenza/ a_ai-asia.htm

34 World Health Organization (2005) Avian influenza - new areas with infection in birds - update 34. In: Disease Outbreak News, 13 Oct 2005

35 Chen H, Smith GJ, Li KS, Wang J, Fan XH, Rayner JM, Vijaykrishna D, Zhang JX, Zhang LJ, Guo CT et al (2006) Establishment of multiple sublineages of 
H5N1 influenza virus in Asia: implications for pandemic control. Proc Natl Acad Sci USA 103: 2845-2850

36 Subbarao K, Klimov A, Katz J, Regnery H, Lim W, Hall H, Perdue M, Swayne D, Bender C, Huang $\mathrm{J}$ et al (1998) Characterization of an avian influenza A (H5N1) virus isolated from a child with a fatal respiratory illness. Science 279: 393-396

37 Yuen KY, Chan PK, Peiris M, Tsang DN, Que TL, Shortridge KF, Cheung PT, To WK, Ho ET, Sung R, Cheng AF (1998) Clinical features and rapid viral diagnosis of human disease associated with avian influenza A H5N1 virus. Lancet 351: 467-471

38 Peiris JS, Yu WC, Leung CW, Cheung CY, Ng WF, Nicholls JM, Ng TK, Chan KH, Lai ST, Lim WL et al (2004) Re-emergence of fatal human influenza A subtype H5N1 disease. Lancet 363: 617-619

39 Peiris M, Yuen KY, Leung CW, Chan KH, Ip PL, Lai RW, Orr WK, Shortridge KF (1999) Human infection with influenza H9N2. Lancet 354: 916-917

40 Fouchier RA, Schneeberger PM, Rozendaal FW, Broekman JM, Kemink SA, Munster V, Kuiken T, Rimmelzwaan GF, Schutten M, Van Doornum et al (2004) Avian influenza A virus (H7N7) associated with human conjunctivitis and a fatal case of acute respiratory distress syndrome. Proc Natl Acad Sci USA 101: 1356-1361

41 Chotpitayasunondh T, Ungchusak K, Hanshaoworakul W, Chunsuthiwat S, Sawanpanyalert P, Kijphati R, Lochindarat S, Srisan P, Suwan P, Osotthanakorn Y et al (2005) Human disease from influenza A (H5N1), Thailand, 2004. Emerg Infect Dis 11: 201-209

42 Tran TH, Nguyen TL, Nguyen TD, Luong TS, Pham PM, Nguyen VC, Pham TS, Vo CD, Le TQ, Ngo TT et al (2004) Avian influenza A (H5N1) in 10 patients in Vietnam. N Engl J Med 350: 1179-1188

43 Areechokchai D, Jiraphongsa C, Laosiritaworn Y, Hanshaoworakul W, O'Reilly M (2006) Investigation of avian influenza (H5N1) outbreak in humans - Thailand, 2004. Morb Mortal Wkly Rep 55 (Suppl 1): 3-6

44 de Jong MD, Bach VC, Phan TQ, Vo MH, Tran TT, Nguyen BH, Beld M, Le TP, Truong HK, Nguyen VV et al (2005) Fatal avian influenza A (H5N1) in a child presenting with diarrhea followed by coma. N Engl J Med 352: 686-691

45 World Health Organization (2006) Epidemiology of WHO-confirmed human cases of avian influenza A (H5N1) infection. Wkly Epidemiol Rec 81: 249-257

$46 \mathrm{Ng} \mathrm{WF}$, To KF, Lam WW, Ng TK, Lee KC (2006) The comparative pathology of severe acute respiratory syndrome and avian influenza A subtype H5N1 - a review. Hum Pathol 37: 381-390

47 To KF, Chan PK, Chan KF, Lee WK, Lam WY, Wong KF, Tang NL, Tsang DN, Sung RY, Buckley TA et al (2001) Pathology of fatal human infection associated with avian influenza A H5N1 virus. J Med Virol 63: 242-246

48 Kuiken T, Rimmelzwaan GF, Van Amerongen G, Osterhaus AD (2003) Pathology of human influenza A (H5N1) virus infection in cynomolgus macaques (Macaca fascicularis). Vet Pathol 40: 304-310

49 Uyeki TM (2003) Influenza diagnosis and treatment in children: a review of studies on clinically useful tests and antiviral treatment for influenza. Pediatr Infect Dis J 22: 164-177 
50 Centers for Disease Control and Prevention (2006) High levels of adamantane resistance among influenza A (H3N2) viruses and interim guidelines for use of antiviral agents - United States, 2005-06 influenza season. Morb Mortal Wkly Rep 55: 44-46

51 Cheung CL, Rayner JM, Smith GJ, Wang P, Naipospos TS, Zhang J, Yuen KY, Webster RG, Peiris JS, Guan Y, Chen H (2006) Distribution of amantadineresistant H5N1 avian influenza variants in Asia. J Infect Dis 193: 1626-1629

52 Ilyushina NA, Govorkova EA, Webster RG (2005) Detection of amantadineresistant variants among avian influenza viruses isolated in North America and Asia. Virology 341: 102-106

53 Le QM, Kiso M, Someya K, Sakai YT, Nguyen TH, Nguyen KH, Pham ND, Ngyen HH, Yamada S, Muramoto Y et al (2005) Avian flu: isolation of drugresistant H5N1 virus. Nature 437: 1108

54 Hayden F, Klimov A, Tashiro M, Hay A, Monto A, McKimm-Breschkin J, Macken C, Hampson A, Webster RG, Amyard M, Zambon M (2005) Neuraminidase inhibitor susceptibility network position statement: antiviral resistance in influenza A/H5N1 viruses. Antivir Ther 10: 873-877

55 Taylor J, Weinberg R, Kawaoka Y, Webster RG, Paoletti E (1988) Protective immunity against avian influenza induced by a fowlpox virus recombinant. Vaccine 6: 504-508

56 Swayne DE, Beck JR, Perdue ML, Beard CW (2001) Efficacy of vaccines in chickens against highly pathogenic Hong Kong H5N1 avian influenza. Avian Dis 45: 355-365

57 Swayne DE, Perdue ML, Beck JR, Garcia M, Suarez DL (2000) Vaccines protect chickens against H5 highly pathogenic avian influenza in the face of genetic changes in field viruses over multiple years. Vet Microbiol 74: 165-172

58 Karaca K, Swayne DE, Grosenbaugh D, Bublot M, Robles A, Spackman E, Nordgren R (2005) Immunogenicity of fowlpox virus expressing the avian influenza virus $\mathrm{H} 5$ gene (TROVAC AIV-H5) in cats. Clin Diagn Lab Immunol 12: $1340-1342$

59 De BK, Shaw MW, Rota PA, Harmon MW, Esposito JJ, Rott R, Cox NJ, Kendal AP (1988) Protection against virulent H5 avian influenza virus infection in chickens by an inactivated vaccine produced with recombinant vaccinia virus. Vaccine 6: 257-261

60 Tumpey TM, Kapczynski DR, Swayne DE (2004) Comparative susceptibility of chickens and turkeys to avian influenza A H7N2 virus infection and protective efficacy of a commercial avian influenza H7N2 virus vaccine. Avian Dis 48: 167-176

61 Halvorson DA (2002) The control of H5 or H7 mildly pathogenic avian influenza: a role for inactivated vaccine. Avian Pathol 31: 5-12

62 Subbarao K, Chen H, Swayne D, Mingay L, Fodor E, Brownlee G, Xu X, Lu X, Katz J, Cox N, Matsuoka Y (2003) Evaluation of a genetically modified reassortant $\mathrm{H} 5 \mathrm{~N} 1$ influenza A virus vaccine candidate generated by plasmid-based reverse genetics. Virology 305: 192-200

63 Liu M, Wood JM, Ellis T, Krauss S, Seiler P, Johnson C, Hoffmann E, Humberd J, Hulse D, Zhang Y et al (2003) Preparation of a standardized, efficacious agricultural H5N3 vaccine by reverse genetics. Virology 314: 580-590 
64 Horimoto T, Takada A, Iwatsuki-Horimoto K, Hatta M, Goto H, Kawaoka Y (2003) Generation of influenza A viruses with chimeric (type A/B) hemagglutinins. $J$ Virol 77: 8031-8038

65 Stech J, Garn H, Wegmann M, Wagner R, Klenk HD (2005) A new approach to an influenza live vaccine: modification of the cleavage site of hemagglutinin. Nat Med 11: 683-689

66 Lu B, Zhou H, Ye D, Kemble G, Jin H (2005) Improvement of influenza A/ Fujian/411/02 (H3N2) virus growth in embryonated chicken eggs by balancing the hemagglutinin and neuraminidase activities, using reverse genetics. $J$ Virol 79: 6763-6771

67 Quinlivan M, Zamarin D, Garcia-Sastre A, Cullinane A, Chambers T, Palese P (2005) Attenuation of equine influenza viruses through truncations of the NS1 protein. J Virol 79: 8431-8439

68 Palker T, Kiseleva I, Johnston K, Su Q, Toner T, Szymkowiak C, Kwan WS, Rubin B, Petrukhin L, Wlochowski J et al (2004) Protective efficacy of intranasal cold-adapted influenza A/New Caledonia/20/99 (H1N1) vaccines comprised of egg- or cell culture-derived reassortants. Virus Res 105: 183-194

69 Subbarao K, Katz JM (2004) Influenza vaccines generated by reverse genetics. Curr Top Microbiol Immunol 283: 313-342

70 Ghendon YZ, Markushin SG, Akopova II, Koptiaeva IB, Nechaeva EA, Mazurkova LA, Radaeva IF, Kolokoltseva TD (2005) Development of cell culture (MDCK) live cold-adapted (CA) attenuated influenza vaccine. Vaccine 23: $4678-4684$

71 Oxford JS, Manuguerra C, Kistner O, Linde A, Kunze M, Lange W, Schweiger B, Spala G, Rebelo de Andrade H, Perez Brena PR et al (2005) A new European perspective of influenza pandemic planning with a particular focus on the role of mammalian cell culture vaccines. Vaccine 23: 5440-5449

72 Subbarao K, Murphy BR, Fauci AS (2006) Development of effective vaccines against pandemic influenza. Immunity 24: 5-9

73 Treanor JJ, Campbell JD, Zangwill KM, Rowe T, Wolff M (2006) Safety and immunogenicity of an inactivated subvirion influenza A (H5N1) vaccine. $N$ Engl J Med 354: 1343-1351

74 Bresson JL, Perronne C, Launay O, Gerdil C, Saville M, Wood J, Hoschler K, Zambon MC (2006) Safety and immunogenicity of an inactivated split-virion influenza A/Vietnam/1194/2004 (H5N1) vaccine: phase I randomised trial. Lancet 367: 1657-1664

75 Garrison MW, Baker DE (1991) Therapeutic advances in the prevention of hepatitis B: yeast-derived recombinant hepatitis B vaccines. DICP 25: 617-627

76 Kuroda K, Hauser C, Rott R, Klenk HD, Doerfler W (1986) Expression of the influenza virus haemagglutinin in insect cells by a baculovirus vector. EMBO J 5: $1359-1365$

77 Vanlandschoot P, Beirnaert E, Neirynck S, Saelens X, Jou WM, Fiers W (1996) Molecular and immunological characterization of soluble aggregated A/ Victoria/3/75 (H3N2) influenza haemagglutinin expressed in insect cells. Arch Virol 141: 1715-1726

78 Wang K, Holtz KM, Anderson K, Chubet R, Mahmoud W, Cox MM (2006) 
Expression and purification of an influenza hemagglutinin - one step closer to a recombinant protein-based influenza vaccine. Vaccine 24: 2176-2185

79 Abe T, Takahashi H, Hamazaki H, Miyano-Kurosaki N, Matsuura Y, Takaku H (2003) Baculovirus induces an innate immune response and confers protection from lethal influenza virus infection in mice. J Immunol 171: 1133-1139

80 Brett IC, Johansson BE (2005) Immunization against influenza A virus: comparison of conventional inactivated, live-attenuated and recombinant baculovirus produced purified hemagglutinin and neuraminidase vaccines in a murine model system. Virology 339: 273-280

81 Crawford J, Wilkinson B, Vosnesensky A, Smith G, Garcia M, Stone H, Perdue ML (1999) Baculovirus-derived hemagglutinin vaccines protect against lethal influenza infections by avian H5 and H7 subtypes. Vaccine 17: 2265-2274

82 Olsen CW, McGregor MW, Dybdahl-Sissoko N, Schram BR, Nelson KM, Lunn DP, Macklin MD, Swain WF, Hinshaw VS (1997) Immunogenicity and efficacy of baculovirus-expressed and DNA-based equine influenza virus hemagglutinin vaccines in mice. Vaccine 15: 1149-1156

83 Lakey DL, Treanor JJ, Betts RF, Smith GE, Thompson J, Sannella E, Reed G, Wilkinson BE, Wright PF (1996) Recombinant baculovirus influenza A hemagglutinin vaccines are well tolerated and immunogenic in healthy adults. $J$ Infect Dis 174: 838-841

84 Powers DC, McElhaney JE, Florendo OA Jr, Manning MC, Upshaw CM, Bentley DW, Wilkinson BE (1997) Humoral and cellular immune responses following vaccination with purified recombinant hemagglutinin from influenza A (H3N2) virus. $J$ Infect Dis 175: 342-351

85 Treanor JJ, Betts RF, Smith GE, Anderson EL, Hackett CS, Wilkinson BE, Belshe RB, Powers DC (1996) Evaluation of a recombinant hemagglutinin expressed in insect cells as an influenza vaccine in young and elderly adults. $J$ Infect Dis 173: 1467-1470

86 Treanor JJ, Schiff GM, Couch RB, Cate TR, Brady RC, Hay CM, Wolff M, She D, Cox MM (2006) Dose-related safety and immunogenicity of a trivalent baculovirus-expressed influenza-virus hemagglutinin vaccine in elderly adults. J Infect Dis 193: 1223-1228

87 Treanor JJ, Wilkinson BE, Masseoud F, Hu-Primmer J, Battaglia R, O'Brien D, Wolff M, Rabinovich G, Blackwelder W, Katz JM (2001) Safety and immunogenicity of a recombinant hemagglutinin vaccine for H5 influenza in humans. Vaccine 19: 1732-1737 